\title{
Thoracolumbar Junction Fractures
}

\author{
Şahin Yüceli ${ }^{1}$, (D) Mustafa Efendioğlu² \\ ${ }^{1}$ Department of Neurosurgery, Neon Hospital, Erzincan, Turkey \\ ${ }^{2}$ Department of Neurosurgery, University of Health Sciences Turkey, Haydarpasa Numune Health Application and Research Center, \\ Istanbul, Turkey
}

\begin{abstract}
Introduction: This study aims to investigate the one level thoracolumbar junction traumatic fracture operations. Methods: Thirty-two patients who were diagnosed and operated for one level traumatic thoracolumbar junction fractures were investigated between 2012-2018 retrospectively in this study.

Results: In this study, 32 patients were included. Mean age of the patients was $51.7 \pm 13.1$ years. Fourteen patients (43.8\%) were females and 18 were males (56.3\%). Twenty-two patients had an L1 fracture (68.8\%), six patients had T11 fracture (18.8\%), and four patients had T12 fracture (12.5\%). The most frequent operations applied to patients were T11-12-L1-2 posterior fusion (PF) to 16 patients (50\%) and T11-12-L2-3 PF and T9-10-11-12-L1 PF to four patients for each (12.5\%). The age distribution between genders was statistically similar $(p=0.12)$. Likewise, the distributions of disease localization $(p=0.92)$ and operation types ( $p=0.91)$ were also similar between female and male patients.

Discussion and Conclusion: Thoracolumbar junction fractures are similar between genders in localization and surgery type. In stable fractures treated conservatively, the use of orthoses has not shown a benefit greater than the use of no immobilization at all. If surgery is chosen, posterior approaches are related to fewer complications than anterior or combined approaches, and percutaneous techniques have shown good results, especially in polytrauma patients.

Keywords: Thoracolumbar junction; traumatic fractures; thoracolumbar junction fractures.
\end{abstract}

$\mathrm{T}$ horacolumbar junction represents the transition zone from a rigid segment to a mobile segment, making it very vulnerable to traumatic lesions ${ }^{[1]}$. The most rigid segment in the spine is the thoracic spine because of the rib cage, whereas the lumbar spine is one of the most flexible regions. The spinal cord lasts between $L 1-L 2$, which means fractures at this level or below, generally displays as cauda equina syndrome. Fractures above L1 can be associated with medulla spinalis compression symptoms.

Thoracolumbar vertebral body fractures are common spinal injuries, and fractures of burst type account for $21 \%$ to $58 \%$ of all thoracolumbar spinal fractures ${ }^{[2]}$. Traffic accidents accounts for $40 \%$ to $45 \%$ of the etiologies, followed by voluntary or involuntary falls ( $15 \%$ to $30 \%)$, sport/leisure accidents (15\% to $25 \%$ ), work accidents and aggressions ${ }^{[3]}$. Young patients are mostly male with high-energy trauma, whereas falls are implicated for older patients. Vertebral neurologic trauma is the main reason for mortality and morbidity. The thoracic and lumbar regions are involved in $50 \%$ of fractures, with neurologic deficit, paraplegia or cauda equina syndrome depending on the region ${ }^{[4]}$. Spinal cord trauma shows high rates of morbidity and mortality, increasing with age and number of associated lesions, es-

Correspondence (İletişim): Şahin Yüceli, M.D. Neon Hastanesi, Beyin ve Sinir Cerrahisi Anabilim Dali, Erzincan, Turkey

Phone (Telefon): +90 5334789790 E-mail (E-posta): yucelisahin24@gmail.com

Submitted Date (Başvuru Tarihi): 27.06.2020 Accepted Date (Kabul Tarihi): 27.06.2020

Copyright 2020 Haydarpaşa Numune Medical Journal

OPEN ACCESS This is an open access article under the CC BY-NC license (http://creativecommons.org/licenses/by-nc/4.0/) 
pecially cranial, thoracic or abdominal trauma ${ }^{[5,6]}$. Kyphotic deformity and neurological deficits are frequently associated with thoracolumbar burst fractures, which are very common in younger patients and could have a considerable impact on their daily physical activities ${ }^{[7]}$.

Many classification systems have been proposed to assist spinal surgeons in the treatment and decision-making for thoracic and lumbar spine injuries. The most commonly used classification systems have been Denis and AOMager ${ }^{[7,8]}$. In 2005, to overcome the limitations of the previous classification systems and with an attempt to develop a grading system with prognostic significance, Vaccaro et al. ${ }^{[9]}$ published a new Thoracolumbar Injury Classification and Severity Score System (TLICS) system based on three domains: injury morphology, the integrity of the posterior ligamentous complex and neurological status. With a score of 3 or less, non-operative management is recommended. Five or more points indicate the need for surgical treatment. A score of 4 does not indicate an ideal treatment and the decision is left to the treating physician.

Treatment goals for thoracolumbar burst fractures include the restoration of spinal stability and alignment, correction of kyphotic deformity and decompression of the spinal canal. Various surgical techniques, including posterior short segment or long segment pedicle screw fixation, direct anterior decompression through corpectomy, and combined methods through anterior and posterior spinal approaches, have since arisen for treatment of thoracolumbar burst fractures ${ }^{[10]}$.

This study aims to investigate the one level thoracolumbar junction traumatic fracture operations.

\section{Materials and Methods}

Thirty-two patients who were diagnosed and operated for one level traumatic thoracolumbar junction fractures were investigated between 2012-2018 retrospectively. The fracture levels selected for this study were T11-T12 and L1 because the surgery for these fractures includes the thoracolumbar junction. The operated levels were noted and compared between genders. Pathologic fractures and fractures above level T11 and below level L1 were excluded from this study.

\section{Statistical Analysis}

The numerical variables were presented as mean and standard deviation, and categorical data were presented as frequency and percent. The comparisons between independent groups were performed using the Mann-Whitney
$\mathrm{U}$ test for numerical data and the Chi-square test for categorical data. A p-value lower than 0.05 was considered as a statistically significant result for that analysis. SPSS 25 (IBM Inc., Armonk, NY, USA) was used for the statistical analyses of this study.

\section{Results}

In this study, 32 patients were included. Mean age of the patients was $51.7 \pm 13.1$ years. Fourteen patients (43.8\%) were females and 18 were males (56.3\%). General demographics of the patients are presented in Table 1.

Twenty-two patients had an L1 fracture (68.8\%), six patients had $\mathrm{T} 11$ fracture $(18.8 \%)$, and four patients had $\mathrm{T} 12$ fracture (12.5\%). The most frequent operations applied to patients were T11-12-L1-2 posterior fusion (PF) to 16 patients (50\%), and T11-12-L2-3 PF and T9-10-11-12-L1 PF to four patients for each (12.5\%). The clinical characteristics of the patients are presented in Table 2.

Comparisons of demographic and clinical characteristics between females and males are presented in Table 3. Accordingly, the mean ages of the female and male patients were $57.7 \pm 10.9$ years and $47.0 \pm 13.2$ years, respectively. The

Table 1. General demographic characteristics of the patients

\begin{tabular}{lcc}
\hline & Mean & SD \\
\hline Age (years) & 51.7 & 13.1 \\
& $\mathbf{n}$ & $\%$ \\
\hline Gender & & \\
Female & 14 & 43.8 \\
Male & 18 & 56.3 \\
\hline
\end{tabular}

Table 2. General clinical characteristics of the patients

\begin{tabular}{lcc}
\hline & $\mathbf{n}$ & $\%$ \\
\hline Disease & & \\
L1 Fracture & 22 & 68.8 \\
T11 Fracture & 6 & 18.8 \\
T12 Fracture & 4 & 12.5 \\
Operation & & \\
T10-11-12-L1 PF & 2 & 6.3 \\
T10-11-12-L1-2 PF & 2 & 6.3 \\
T10-11-12-L1-2-3 PF & 2 & 6.3 \\
T11-12-L1-2 PF & 16 & 50.0 \\
T11-12-L2-3 PF & 4 & 12.5 \\
T12-L1-2 PF & 2 & 6.3 \\
T9-10-11-12-L1 PF & 4 & 12.5 \\
\hline
\end{tabular}

PF: Posterior Fusion. 
Table 3. Comparisons of the demographic and clinical characteristics between genders

\begin{tabular}{|c|c|c|c|c|c|}
\hline & \multicolumn{2}{|c|}{ Female } & \multicolumn{2}{|c|}{ Male } & \multirow[t]{2}{*}{$\mathbf{p}$} \\
\hline & Mean & SD & Mean & SD & \\
\hline \multirow[t]{2}{*}{ Age (years) } & 57.7 & 10.9 & 47.0 & 13.2 & 0.12 \\
\hline & $\mathbf{n}$ & $\%$ & $\mathbf{n}$ & $\%$ & $\mathbf{p}$ \\
\hline Disease & & & & & 0.92 \\
\hline L1 Fracture & 10 & 71.4 & 12 & 66.7 & \\
\hline T11 Fracture & 2 & 14.3 & 4 & 22.2 & \\
\hline T12 Fracture & 2 & 14.3 & 2 & 11.1 & \\
\hline Operation & & & & 0.91 & \\
\hline T10-11-12-L1 PF & - & - & 2 & 11.1 & \\
\hline T10-11-12-L1 PF & 2 & 14.3 & - & - & \\
\hline T10-11-12-L1-2-3 PF & - & - & 2 & 11.1 & \\
\hline T11-12-L1-2 PF & 6 & 14.3 & 10 & 55.6 & \\
\hline T11-12-L2-3 PF & 2 & 14.3 & 2 & 11.1 & \\
\hline T12-L1-2 PF & 2 & 14.3 & - & - & \\
\hline T9-10-11-12-L1 PF & 2 & 14.3 & 2 & 11.1 & \\
\hline
\end{tabular}

age distribution between genders was statistically similar $(p=0.12)$. Likewise, the distributions of disease localization ( $p=0.92)$ and operation types ( $p=0.91$ ) were also similar between female and male patients.

\section{Discussion}

Traumatic fractures of the thoracolumbar spine are relatively common occurrences that can be a source of pain and disability. Similarly, osteoporotic vertebral fractures are also frequent events and represent a significant health issue specific to the elderly.

Conservative treatment is proposed in stable injuries, including simple compression or stable burst fractures with no significant posterior osteoligamentous disruption or neurological complications; this means a TLICS classification of 3 points or less ${ }^{[9]}$. Neurologically intact patients with traumatic thoracolumbar fractures can commonly be treated nonoperatively with bracing.

Before the development of surgical techniques and instrumentation, bed rest and bracing were the only modalities available for the treatment of thoracolumbar fractures. Currently, there are many different surgical approaches and instrumentation techniques for thoracolumbar fractures. However, bracing remains a mainstay in the treatment of many thoracolumbar injuries ${ }^{[11]}$. Non-operative treatment is not suitable for patients with neurological deficits or highly unstable fractures.

Surgical treatment is proposed when patients have unsta- ble burst fractures (PLC complex injury), burst fractures with neurological deficit or a distraction/rotational injuries with or without neurological injury. Surgery is frequently indicated with a TLICS classification of 5 points or above. Posterior transpedicular screw fixation was initially reported by Boucher in $1959^{[12]}$. Since then, modern instrumentation systems have been developed. These systems control segmental motions in three dimensions, preserve motion segments, avoid long fusions, and provide a more stable construct ${ }^{[13]}$. As with all surgical implants, transpedicular screw instrumentation maintains reduction until the bony union is achieved.

Aly et al. ${ }^{[14]}$ evaluated 365 patients who were included in this meta-analysis. Results were expressed as risk difference for dichotomous outcomes and standard mean difference for continuous outcomes with a $95 \%$ confidence interval. Baseline characteristics were similar between the short and long segment fixation groups. No significant difference was identified between the two groups regarding the radiological outcomes, functional outcome, neurologic improvement, and implant failure rate. The results of this meta-analysis suggested that extension of fixation was not necessary when thoracolumbar burst fracture was treated by posterior pedicle screw fixation ${ }^{[14]}$.

Diniz et al. ${ }^{[15]}$ investigated 220 patients and an average follow-up time of 69.1 months and they reported that the use of arthrodesis did not improve clinical outcomes. However, it was associated with increased surgical time and higher intraoperative bleeding and did not promote significant improvement in radiological parameters.

In our series, we mostly include the thoracolumbar segment and fractured level for instrumentation (T10-T11T12-L1) and prefer arthrodesis. There is not a consensus for these kinds of surgery and it is upon the surgeons' experience.

\section{Conclusion}

Thoracolumbar junction fractures are similar between genders in localization and surgery type. In stable fractures treated conservatively, the use of orthoses has not shown a benefit greater than the use of no immobilization at all. There is a lack of evidence to support greater beneficial outcomes from these surgical options when compared with conservative measures. If surgery is chosen, posterior approaches are related to fewer complications than anterior or combined approaches, and percutaneous techniques have shown good results, especially in polytrauma patients. 
Ethics Committee Approval: Rethrospective study.

Peer-review: Externally peer-reviewed.

Authorship Contributions: Concept: Ş.Y., M.E.; Design: Ş.Y., M.E.; Data Collection or Processing: Ş.Y.; Analysis or Interpretation: Ş.Y., M.E.; Literature Search: Ş.Y., M.E.; Writing: Ş.Y., M.E.

Conflict of Interest: None declared.

Financial Disclosure: The authors declared that this study received no financial support.

\section{References}

1. Cahueque M, Cobar A, Zuñiga C, Caldera G. Management of burst fractures in the thoracolumbar spine. J Orthop 2016;13:278-81. [CrossRef]

2. Dai LY, Yao WF, Cui YM, Zhou Q. Thoracolumbar fractures in patients with multiple injuries: diagnosis and treatment-a review of 147 cases. J Trauma 2004;56:348-55. [CrossRef]

3. Holmes JF, Miller PQ, Panacek EA, Lin S, Horne NS, Mower WR. Epidemiology of thoracolumbar spine injury in blunt trauma. Acad Emerg Med 2001;8:866-72. [CrossRef]

4. Charles YP, Steib JP. Management of thoracolumbar spine fractures with neurologic disorder. Orthop Traumatol Surg Res 2015;101:S31-40. [CrossRef]

5. Kazanci B, Ozdogan S, Kahveci R, Gokce EC, Yigitkanli K, Gokce A, et al. Neuroprotective Effects of Pregabalin Against Spinal Cord Ischemia-Reperfusion Injury in Rats. Turk Neurosurg 2017;27:952-61. [CrossRef]

6. McHenry TP, Mirza SK, Wang J, Wade CE, O'Keefe GE, Dailey AT, et al. Risk factors for respiratory failure following operative stabilization of thoracic and lumbar spine fractures. J Bone Joint Surg Am 2006;88:997-1005. [CrossRef]

7. Denis $F$. The three column spine and its significance in the classification of acute thoracolumbar spinal injuries. Spine (Phila Pa 1976) 1983;8:817-31. [CrossRef]

8. Magerl F, Aebi M, Gertzbein SD, Harms J, Nazarian S. A comprehensive classification of thoracic and lumbar injuries. Eur Spine J 1994;3:184-201. [CrossRef]

9. Vaccaro AR, Lehman RA Jr, Hurlbert RJ, Anderson PA, Harris $M$, Hedlund $R$, et al. A new classification of thoracolumbar injuries: the importance of injury morphology, the integrity of the posterior ligamentous complex, and neurologic status. Spine (Phila Pa 1976) 2005;30:2325-33. [CrossRef]

10. Tezeren G, Kuru I. Posterior fixation of thoracolumbar burst fracture: short-segment pedicle fixation versus long-segment instrumentation. J Spinal Disord Tech 2005;18:485-8. [CrossRef]

11. Chang V, Holly LT. Bracing for thoracolumbar fractures. Neurosurg Focus 2014;37:E3. [CrossRef]

12. Boucher $\mathrm{HH}$. A method of spinal fusion. J Bone Joint Surg Br 1959;41-B:248-59. [CrossRef]

13. Roy-Camille R, Saillant G, Mazel C. Internal fixation of the lumbar spine with pedicle screw plating. Clin Orthop Relat Res 1986;7-17. [CrossRef]

14. Aly TA. Short Segment versus Long Segment Pedicle Screws Fixation in Management of Thoracolumbar Burst Fractures: Meta-Analysis. Asian Spine J 2017;11:150-60. [CrossRef]

15. Diniz JM, Botelho RV. Is fusion necessary for thoracolumbar burst fracture treated with spinal fixation? A systematic review and meta-analysis. J Neurosurg Spine 2017;27:584-92. 